\title{
Qualidade microbiológica do queijo artesanal tipo "manteiga" cormercializado em um município do Amapá
}

\author{
Microbiological quality of artisanal cheese type "butter" marked in a municipality of Amapá \\ Calidad microbiológica de queso artesanal tipo "manteca" comercializado en un municipio \\ de Amapá
}

Gleicyanne Furtado Frazão ${ }^{1}$, Claude Porcy ${ }^{1}$, Neliane de Oliveira Moreira' ${ }^{1}$, Raphaela Lobato Lopes ${ }^{1}$, Dirley Cardoso Moreira² ${ }^{2}$ Rubens Alex de Oliveira Menezes ${ }^{2 *}$, Flávio Henrique Ferreira Barbosa ${ }^{3}$.

\section{RESUMO}

Objetivo: Analisar a qualidade microbiológica dos queijos tipo manteiga comercializados em feiras livres, em um município do Amapá. Métodos: Trata-se de estudo transversal descritivo, conduzido por meio de parâmetros microbiológicos, que medem a qualidade desse alimento. Foram analisadas 10 amostras do produto, sendo realizadas análises de coliformes fecais e totais através da técnica de Número Mais Provável (NMP), método que permite estimar a densidade de microrganismos viáveis presentes em uma amostra sob análise e realizadas identificações pelo equipamento MicroScan Walkwall96, visando detectar presença de Salmonella e Staphylococcus aureus. Resultados: De acordo com a tabela do (NMP) as amostras se mostraram adequadas para o consumo, as amostras analisadas por automação, pesquisa de Salmonella $e$ Staphylococcus aureus ausência das bactérias. Entretanto, foram identificadas a presença de Klebsiella pneumoniae, Proteus mirabilis, Staphylococcus xylosus e Staphylococcus sciuri. Conclusão: Os resultados demonstraram que os queijos tipo manteiga produzidos artesanalmente e comercializados nas feiras pesquisadas, não se encontram de acordo com a legislação vigente, por estarem contaminados por microrganismos que podem causas infecções de origem alimentar.

Palavras-chave: Queijo artesanal, Qualidade microbiológica, Intoxicação alimentar.

\begin{abstract}
Objective: To analyze the microbiological quality of butter-type cheeses marketed in open markets, in a municipality in Amapá. Methods: This is a descriptive cross-sectional study, conducted through microbiological parameters, which measure the quality of this food. Ten samples of the product were analyzed, and analyzes of fecal and total coliforms were performed using the Most Likely Number (NMP) technique, a method that allows estimating the density of viable microorganisms present in a sample under analysis and identification by the MicroScan Walkwall96 equipment, aiming at detect the presence of Salmonella and Staphylococcus aureus. Results: According to the (NMP) table, the samples were shown to be suitable for consumption, the samples analyzed by automation, research of Salmonella and Staphylococcus aureus absence of bacteria. However, the presence of Klebsiella pneumoniae, Proteus mirabilis, Staphylococcus xylosus and Staphylococcus sciuri were identified. Conclusion: The results showed that the butter-type cheeses produced by hand and sold at the researched fairs are not in accordance with current legislation, as microorganisms that can cause food-borne infections contaminate them.
\end{abstract}

Keywords: Artisanal cheese, Microbiological quality, Food poisoning.

\footnotetext{
1 Faculdade Estácio de Macapá, Macapá - AP.

2 Universidade Federal do Amapá (UNIFAP), Macapá - AP. *E-mail: rubens.alex@unifap.br

3 Universidade Federal de Sergipe (UFS), São Cristóvão - SE.
} 


\section{RESUMEN}

Objetivo: Analizar la calidad microbiológica de quesos tipo mantequilla comercializados en mercados abiertos, en un municipio de Amapá. Métodos: Se trata de un estudio descriptivo transversal, realizado a través de parámetros microbiológicos, que miden la calidad de este alimento. Se analizaron diez muestras del producto y se realizaron análisis de coliformes fecales y totales mediante la técnica Most Likely Number (NMP), método que permite estimar la densidad de microorganismos viables presentes en una muestra en análisis e identificación por el equipo MicroScan Walkwall96, con el objetivo de detectar la presencia de Salmonella y Staphylococcus aureus. Resultados: De acuerdo con la tabla (NMP), las muestras se mostraron aptas para el consumo, las muestras analizadas por automatización, investigación de Salmonella y Staphylococcus aureus ausencia de bacterias. Sin embargo, se identificó la presencia de Klebsiella pneumoniae, Proteus mirabilis, Staphylococcus xylosus y Staphylococcus sciuri. Conclusión: Los resultados mostraron que los quesos tipo mantequilla elaborados artesanalmente y comercializados en las ferias investigadas no se ajustan a la legislación vigente, ya que están contaminados por microorganismos que pueden provocar infecciones de origen alimentario.

Palabras clave: Queso artesanal, Calidad microbiológica, Intoxicación alimentaria.

\section{INTRODUÇÃO}

Historicamente, os dados relacionados à produção de queijos no Brasil são controversos, tanto em relação ao período quanto às regiões em que essa prática foi iniciada. Entretanto, os queijos artesanais brasileiros provavelmente foram originados de Portugal e com a vinda de imigrantes dinamarqueses e holandeses que se fixaram em determinadas regiões do estado de Minas Gerais. Desde então, diferentes tipos de queijos artesanais foram desenvolvidos, sendo o estado de Minas Gerais o maior a produzir queijos no Brasil e o primeiro a desenvolver uma legislação própria que viabilizou a produção artisanal (PERKINS E, 2016; ARAÚJO JPA, et al., 2020).

O queijo tem sido utilizado ao longo do tempo como uma forma de preservação do leite, principalmente para os produtores de leite no interior do estado que se situam longe dos grandes centros consumidores (AZEVEDO ACA, et al., 2017). Ademais, estudos microbiológicos realizados nas últimas décadas têm demonstrado a presença de diversos tipos de bactérias patogênicas nos queijos produzidos no Brasil. Ademais, os produtos derivados do leite têm sido implicados como veículo de bactérias patogênicas. Desta maneira, a qualidade microbiológica desses produtos deve apresentar condições apropriadas para o consumo humano (DUPIN LV, 2020).

Adicionalmente, o estado do Amapá possui um plantel de bubalinos que corresponde a $19,41 \%$ do total nacional e $28,61 \%$ do total de animais da região Norte. As propriedades com bubalinos no estado correspondem a $4,23 \%$ do total de propriedades bubalinocultoras nacionais e $9,07 \%$ das que se encontram na região Norte. Ademais, as regiões amazônicas possuem muitas áreas que alagam facilmente, isso contribui para o desenvolvimento dos rebanhos de búfalos, de modo que os produtores artesanais de queijos feitos com o leite desse animal, geram renda para suas famílias e também para as regiões produtoras (BRASIL, 2013; SEIXAS VNC, 2014; MARINI JA, 2015).

Um dos principais produtos derivados do leite é o queijo, este alimento pode ser responsável por transmissões de patógenos de origem alimentar. O queijo pode ser denominado como produto perecível, além de possuir um alto valor de umidade em sua composição, isso contribui para a proliferação microbiana, favorecendo o risco de desenvolvimento de intoxicações alimentares na população (OLIVEIRA KML, et al., 2015). A análise microbiológica é muito importante para conhecer, realmente a qualidade higiênica com o qual foi elaborada este alimento, além do mais, alimentos que são preparados com um manejo maior pelas pessoas responsáveis por sua elaboração, e que iram continuar em temperatura ambiente por um tempo longo posteriormente a sua fabricação, são apontados como alimentos de alto risco de proliferação microbiana por se tratarem de alimento que utilizam leite cru em sua composição (MATSUMOTO AY, et al., 2016). 
A cadeia de prevenção dos alimentos de origem animal deve ser eficaz desde a origem desse alimento até o consumidor final, isso favorece a produção de matéria prima de boa qualidade, isto se aplica também a fabricação de queijo tipo manteiga produzidos de forma artesanal (GERMANO PML e GERMANO MIS, 2015). Adicionalmente, o regulamento técnico de identidade e qualidade do Ministério da Agricultura Pecuária e Abastecimento (MAPA), entende-se por Queijo de Manteiga, o produto obtido mediante coagulação do leite com emprego de ácidos orgânicos de grau alimentício, cuja massa é submetida à dessoragem, lavagem e fusão, com acréscimo exclusivamente de manteiga de garrafa ou manteiga do sertão (BRASIL, 2001a).

A denominação Queijo de Manteiga está reservada ao produto cuja base láctea não contenha gordura e/ou proteína e/ou outros produtos de origem não láctea. Quanto a sua classificação, é um queijo com teor de gordura variando entre $25 \%$ e $55 \%$, devendo apresentar um teor máximo de umidade de $54,9 \% \mathrm{~m} / \mathrm{m}$ (BRASIL, 2001a). O queijo produzido em diferentes regiões possui etapas de fabricação similares. Porém, apresentam características sensoriais distintas, devido a particularidades de produção e características específicas dos locais em que são produzidos. O modo de produção associado a padrões culturais e regionais, além de características geoclimáticas, determinam a composição de microbiomas específicos de queijos artesanais, que são produzidos em diferentes regiões do Brasil (PERKINS E, 2016; ARAÚJO JPA, et al., 2020).

Os queijos são, em geral, produtos muito manipulados e passíveis de contaminação, estas condições podem ser agravadas, quando processados com leite cru, sem o emprego das práticas e tecnologias adequadas. A pesquisa microbiológica permite, entender as condições sob as quais um produto foi produzido, sendo fundamental para a garantia da saúde do consumidor. Os coliformes termotolerantes constituem um subgrupo dos coliformes totais, sendo sua presença indicativo de contaminação fecal (AZEVEDO ACA, et al., 2017). Ademais, o manuseio intenso, de alimentos sob condições precárias de higiene é indicativo de contaminação por Echerichia coli, Staphylococcus aureus e Salmonella sp a partir da pele, boca e das fossas nasais dos manipuladores, bem como da limpeza e da sanitização inadequada dos materiais e equipamentos (MAIA ICP, et al., 2011; AZEVEDO ACA, et al., 2017).

De forma complementar, os contaminantes microbiológicos mais freqüentes encontrados são fungos, virus e bactérias, além de macroorganismos como moscas, carrapatos e larvas de mosquitos. Isso tudo pode ocasionar doenças na população como infecções e intoxicações alimentares (principalmente à toxina do Staphylococcus aureus), febres tifóide e paratifóide, salmonelose e intoxicações estreptocócicas (SANTOS NS, et al., 2019). Adicionalmente, à avaliação da qualidade desses queijos, são de extrema relevancia, pois através de análises microbiológicas prevista em legislação, pode-se caracterizar como alimentos saudável e/ou impróprios para o consumo, garantindo a segurança ao consumidor (SILVA F e SILVA G, 2013; AZEVEDO ACA, et al., 2017).

Neste sentido o controle higiênico - sanitário, dos alimentos de origem animal permite, o controle de diversas patogenias que possam atingir o homem por meio de alimentos contaminados por microrganismos causadores de doenças (BRINQUES GB, 2015). No que se refere a este tipo de queijo, a bibliografia é escassa se limitando a descrição de sua composição e possíveis alterações da composição e qualidade durante a estocagem. Ademais, dentre os produtos de laticínios fabricados no Amapá, o queijo artezanal tipo "Manteiga" é um dos mais difundidos. Essa pesquisa visa esclarecer por meio de parâmetros microbiológicos a qualidade desses alimentos, tendo como objetivo: Analisar a qualidade microbiológica dos queijos tipo manteiga comercializados em feiras livres, no município de Macapá-AP.

\section{MÉTODOS}

Foram analisadas 10 amostras de queijo artesanal tipo Manteiga comercializados nas feiras do produtor dos bairros Buritizal e Jardim Felicidade, localizadas na Cidade de Macapá-AP, essas amostras foram colhidas de forma aleatória com os comerciantes do respectivo produto, que estavam no local no momento da coleta. As amostras foram transportadas em caixa isotérmica na qual continha gelo reciclável, para manter a temperatura das amostras de queijo, até o momento de serem analisadas no laboratório de microbiologia da faculdade Estácio Macapá, essas amostras foram processadas e identificadas com números de 01 á 10 as mesmas foram submetidas a análises microbiológicas para determinação de coliformes fecais e totais, Staphylococcus aureus e Salmonella. 
Para a pesquisa de coliformes fecais e totais, foram utilizados o método do Número Mais Provável (NMP), para esse procedimento foram retirados de cada amostra a quantidade de $10 \mathrm{~g}$ do alimento no qual foi colocado em sacos plásticos estéreis com o objetivo de colher alíquotas do material em estudo, esse procedimento foi feito de maneira asséptica para evitar contaminação com o meio externo, logo após foi preparada diluições decimais, onde foi adicionado inicialmente em um erlenmeyer $90 \mathrm{~mL}$ de água tamponada e assim adicionados as $10 \mathrm{~g}$ da amostra $1\left(10^{-1}\right)$ e em seguida houve a homogeneização em stomacher $\mathrm{e}$ transferido $1 \mathrm{~mL}$ da preparação para outro erlenmeyer que continha $9 \mathrm{~mL}$ de água tamponada havendo assim a diluição em $10^{-2}$.

O procedimento foi repetido para a preparação da diluição $10^{-3}$. Após tal processo de cada erlenmeyer houve a distribuição de $1 \mathrm{~mL}$ da preparação citada em três tubos de ensaio contendo tubos Durhan e caldo Lactosado, cada tubo foi identificado, com as respectivas diluições: $10^{-1}, 10^{-2}$ e $10^{-3}$ as análises foram realizadas em triplicata, as amostras foram incubadas a $37^{\circ} \mathrm{C}$ por 48 horas (Figura 1).

Figura 1 - Método do (NMP), para contagem de coliformes.

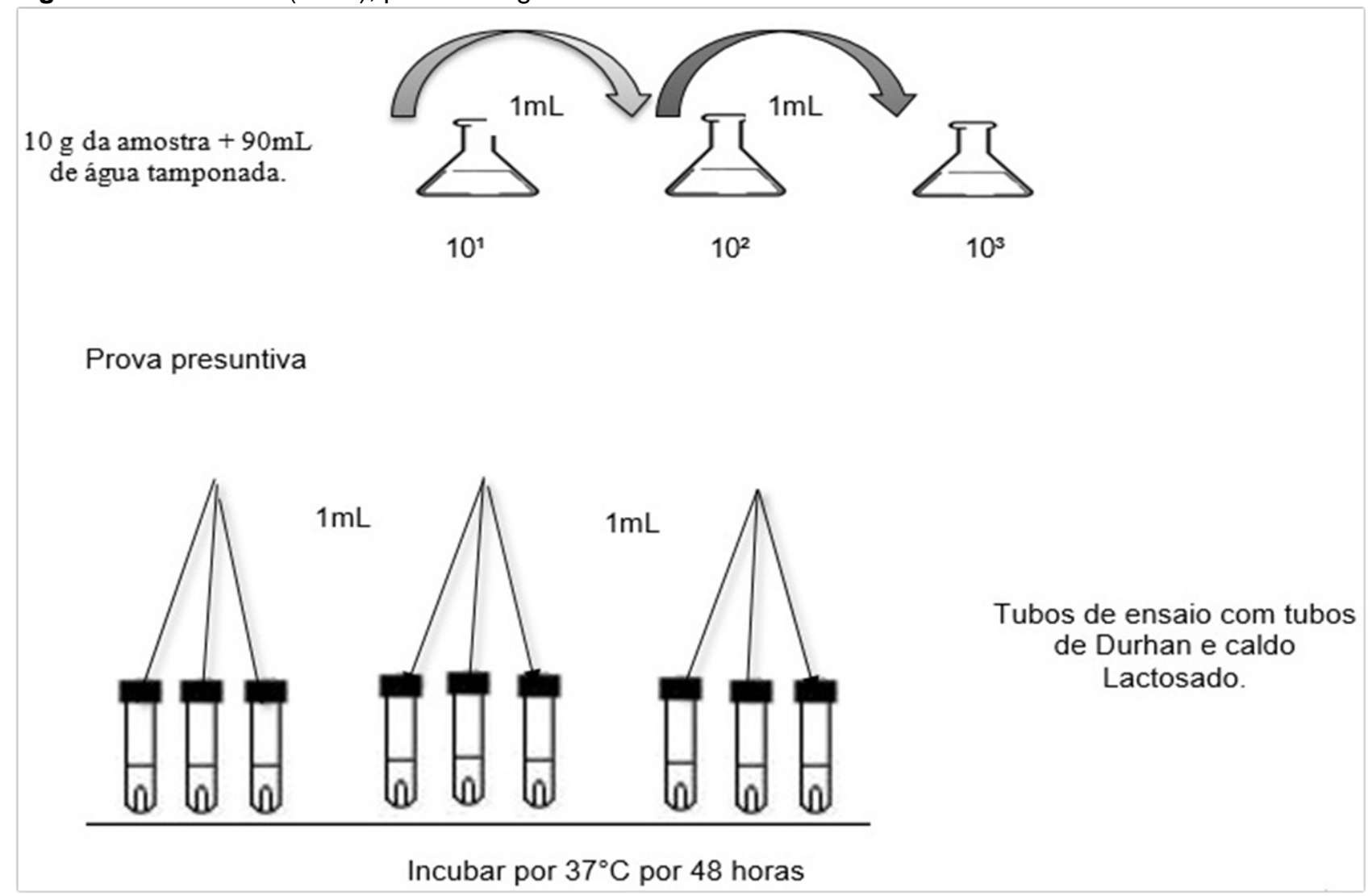

Fonte: Frazão GF, et al., 2020.

Após 48 horas a $37^{\circ} \mathrm{C}$, foram transferidos com alças de platina de $10 \mu \mathrm{l}$, o material dos tubos de ensaio que se apresentaram positivos (presença de gás), para tubos de ensaio contendo tubos de Durhan e caldo verde brilhante (CLBVB), foram incubadas á $37^{\circ} \mathrm{C}$ por 48 horas novamente. Após o tempo citado os tubos com caldo verde brilhante que estavam positivos para cada diluição foram separados e assim anotados os referidos resultados. Em seguida foi consultada a tabela do Número Mais Provável (método NMP) para coliformes totais.

Houve ainda a realização da prova confirmatória para coliformes fecais, assim foi transferido com alças de platina de $10 \mu \mathrm{l}$, o material dos tubos de ensaio que se apresentaram positivos (presença de gás) com caldo Lactosado para tubos de ensaios contendo caldo E.C, estes foram incubados a $44,5^{\circ} \mathrm{C}$ por 24 horas. Após às $24 \mathrm{~h}$ foi anotado o número de tubos positivos para cada diluição, e a tabela do Número Mais Provável (método NMP) foi consultada para determinar a quantidade de coliformes fecais. 
Para a pesquisa de Salmonella, foram utilizados $25 \mathrm{~g}$ do queijo, que foi macerado assepticamente e colocado em um Erlenmeyer contendo $200 \mathrm{ml}$ de caldo Lactosado (C.L), este foi incubado a $37^{\circ} \mathrm{C}$ por 24 horas, seguidamente foi retirado do Erlenmeyer uma alíquota de $1 \mathrm{~mL}$ e colocado em um tubo de ensaio enriquecido com caldo Tetrationato. Foi feita a mistura da solução, e em seguida foi incubada a $43^{\circ} \mathrm{C}$ por 24 horas, seguidamente foi feito o semeio de forma pura, ou seja, sem diluições decimais, para isolamento de colônias típicas, nesta semeadura foram utilizadas placas de Petri enriquecidas com ágar SS ( Salmonella-Shigella) e em seguida foram incubadas a $37^{\circ} \mathrm{C}$ por 24 horas. Após o tempo decorrido as placas foram levadas para 0 laboratório Acqualitybio para dar prosseguimento das análises microbiológicas de forma automatizadas no aparelho MicroScan Walkwall96.

Para a contagem de Staphylococcus aureus, foram pesados $10 \mathrm{~g}$ do queijo e colocados em sacos plásticos estéreis, foi adicionado $90 \mathrm{~mL}$ de solução salina estéril, e homogeneizado, em seguida foi preparada, diluições decimais $10^{-1}, 10^{-2}$ e $10^{-3}$ em tubos de ensaio contendo $9 \mathrm{~mL}$ de solução salina estéril, em seguida foi adicionado $1 \mathrm{~mL}$ da amostra para cada diluição e cada uma foi agitada, seguidamente foram semeadas em placas de Petri contendo ágar manitol salgado, cada placa foi semeada de acordo com suas respectivas diluições decimais, o conteúdo das diluições foi espalhado na superfície das placas com alça de Drigalsky e foram incubadas a $35^{\circ} \mathrm{C}$ por 48 horas. Após 48 horas essas placas foram levadas ao laboratório Acqualitybio para dar prosseguimento das análises microbiológicas de forma automatizadas no aparelho MicroScan Walkwall96.

A análise dos dados coletados a partir dos resultados dos ensaios microbiológicas foram inicialmente análisados de forma exploratória e organizados em tabelas e planilhas usando como ferramenta o Software Microsoft Excel, versão $2010 \AA$, apresentados por meio dos valores mínimos e máximos observados para cada grupo de microorganismos. Para interpretação dos resultados obtidos neste estudo, baseou-se nos padrões microbiológicos estabelecidos pela quantidade de coliformes totais e fecais nas amostras de queijo tipo manteiga utilizado o método do Número Mais Provável (NMP) e posteriormente submetido ao programa estatístico BioEstat 5.0. Para o presente artigo foi solicitado à dispensa do consentimento livre e esclarecido, pois o projeto não utilizou de pesquisa com seres humanos e/ou animais, sendo submetidos ao comitê de ética, para obtenção do protocolo de isenção.

\section{RESULTADOS}

Para se determinar a quantidade de coliformes totais e fecais nas amostras de queijo tipo manteiga foi utilizado o método do Número Mais Provável (NMP), cada resultado foi calculado de acordo com a tabela referente ao método supracitado (Tabela 1). Ademais, os resultados apresentados na referida tabela apresentam um NMP por grama de amostra $(<3 \mathrm{NMP} / \mathrm{g})$, dentro do aceitável para o consumo, segundo o que preconiza a legislação da vigilância sanitaria (BRASIL, 2001b).

Tabela 1 - Análise microbiológica do queijo tipo manteiga, determinação de coliformes fecais, método do Número Mais Provável (NMP) em caldo EC.

\begin{tabular}{ccccccc}
\hline $\begin{array}{c}\text { Queijo tipo } \\
\text { Manteiga }\end{array}$ & $\mathbf{N}^{\circ}$ & $\begin{array}{c}\text { Feira do Produtor } \\
\text { Bairro }\end{array}$ & $\begin{array}{c}\text { Diluição } \\
\mathbf{1 0}^{\mathbf{1}}\end{array}$ & $\begin{array}{c}\text { Diluição } \\
\mathbf{1 0}^{\mathbf{2}}\end{array}$ & $\begin{array}{c}\text { Diluição } \\
\mathbf{1 0}^{\mathbf{3}}\end{array}$ & $\begin{array}{c}\text { Resultado } \\
\text { NMP }\end{array}$ \\
\hline Amostra & 01 & Buritizal & 0 & 0 & 0 & $<3$ \\
Amostra & 02 & Buritizal & 0 & 0 & 0 & $<3$ \\
Amostra & 03 & Buritizal & 0 & 0 & 0 & $<3$ \\
Amostra & 04 & Buritizal & 0 & 0 & 0 & $<3$ \\
Amostra & 05 & Buritizal & 0 & 0 & 0 & $<3$ \\
Amostra & 06 & Jardim Felicidade I & 0 & 0 & 0 & $<3$ \\
Amostra & 07 & Jardim Felicidade I & 0 & 0 & 0 & $<3$ \\
Amostra & 08 & Jardim Felicidade I & 0 & 0 & 0 & $<3$ \\
Amostra & 09 & Jardim Felicidade I & 0 & 0 & 0 & $<3$ \\
Amostra & 10 & Jardim Felicidade I & 0 & 0 & 0 & $<3$
\end{tabular}

Fonte: Frazão GF, et al., 2020. 
Na Tabela 2 observamos os coliformes totais através da prova confirmatória pelo caldo verde brilhante. Adicionalmente, com relação ao coliformes totais sete de dez amostras que estavam em caldo verde brilhante, apresentaram NMP por grama do alimento menor que três, e em apenas três o NMP foi alterado de forma leve, mas não fugiu do que determina a Resolução RDC nำ12/2001 da ANVISA (BRASIL, 2001b).

Tabela 2 - Coliformes Totais: Prova confirmatória Caldo Verde brilhante (CLBVB).

\begin{tabular}{|c|c|c|c|c|c|c|}
\hline $\begin{array}{l}\text { Queijo tipo } \\
\text { Manteiga }\end{array}$ & $\mathbf{N}^{\circ}$ & $\begin{array}{c}\text { Feira do Produtor } \\
\text { Bairro }\end{array}$ & $\begin{array}{c}\text { Diluição } \\
10^{1}\end{array}$ & $\begin{array}{c}\text { Diluição } \\
10^{2}\end{array}$ & $\begin{array}{c}\text { Diluição } \\
10^{3}\end{array}$ & $\begin{array}{l}\text { Resultado } \\
\text { NMP }\end{array}$ \\
\hline Amostra & 01 & Buritizal & 0 & 0 & 0 & $<3$ \\
\hline Amostra & 02 & Buritizal & 0 & 0 & 0 & $<3$ \\
\hline Amostra & 03 & Buritizal & 0 & 0 & 0 & $<3$ \\
\hline Amostra & 04 & Buritizal & 0 & 0 & 0 & $<3$ \\
\hline Amostra & 05 & Buritizal & 0 & 1 & 0 & 3 \\
\hline Amostra & 06 & Jardim Felicidade I & 0 & 0 & 0 & $<3$ \\
\hline Amostra & 07 & Jardim Felicidade I & 0 & 0 & 0 & $<3$ \\
\hline Amostra & 08 & Jardim Felicidade I & 0 & 0 & 0 & $<3$ \\
\hline Amostra & 09 & Jardim Felicidade I & 1 & 1 & 0 & 7 \\
\hline Amostra & 10 & Jardim Felicidade I & 1 & 1 & 1 & 11 \\
\hline
\end{tabular}

Fonte: Frazão GF, et al., 2020.

Adicionalmente, para a pesquisa de Salmonella $s p$, foram analisadas dez amostras de queijo, todas identificadas de acordo com a feira e o bairro onde foram adquiridas, as placas contendo ágar SS, sendo que das dez placas semeadas todas tiveram crescimento bacteriano. Com relação a contagem de Salmonella $s p$, das dez amostras analisadas de queijo tipo manteiga verificou-se a ausência do referido microorganismo. Embora constatou-se a presença de outras bactérias como: Proteus mirabilis, Stapylococcus xylosus, Staphylococcus Sciuri e Klebsiella Pneumoniae (Tabela 3).

Tabela 3 - Resultado das análises microbiológica das amostras de queijo tipo manteiga.

\begin{tabular}{|c|c|c|c|c|c|c|c|}
\hline Queijo & $\begin{array}{c}\text { Feira } \\
\text { do } \\
\text { Produto }\end{array}$ & Salmonella & $\begin{array}{c}\text { Klebsiella } \\
\text { pneumoniae }\end{array}$ & $\begin{array}{l}\text { Proteus } \\
\text { mirabilis }\end{array}$ & $\begin{array}{l}\text { Staphylo- } \\
\text { coccus } \\
\text { aureus }\end{array}$ & $\begin{array}{l}\text { Staphylo- } \\
\text { coccus } \\
\text { xylosus }\end{array}$ & $\begin{array}{c}\text { Staphylo- } \\
\text { coccus } \\
\text { sciuri }\end{array}$ \\
\hline 01 & Buritizal & Ausente & Ausente & Ausente & Ausente & Presente & Ausente \\
\hline 02 & Buritizal & Ausente & Ausente & Ausente & Ausente & Presente & Ausente \\
\hline 03 & Buritizal & Ausente & Ausente & Ausente & Ausente & Presente & Ausente \\
\hline 04 & Buritizal & Ausente & Ausente & Ausente & Ausente & Presente & Ausente \\
\hline 05 & Buritizal & Ausente & Ausente & Ausente & Ausente & Presente & Ausente \\
\hline 06 & $\begin{array}{l}\text { Jardim } \\
\text { Felicidade }\end{array}$ & Ausente & Presente & Presente & Ausente & Ausente & Presente \\
\hline 07 & $\begin{array}{l}\text { Jardim } \\
\text { Felicidade }\end{array}$ & Ausente & Presente & Presente & Ausente & Ausente & Ausente \\
\hline 08 & $\begin{array}{l}\text { Jardim } \\
\text { Felicidade }\end{array}$ & Ausente & Presente & Presente & Ausente & Ausente & Ausente \\
\hline 09 & $\begin{array}{l}\text { Jardim } \\
\text { Felicidade }\end{array}$ & Ausente & Presente & Presente & Ausente & Ausente & Ausente \\
\hline 10 & $\begin{array}{l}\text { Jardim } \\
\text { Felicidade }\end{array}$ & Ausente & Presente & Presente & Ausente & Ausente & Ausente \\
\hline Total & 10 & 10 & 05 & 05 & 10 & 05 & 01 \\
\hline
\end{tabular}

Fonte: Frazão GF, et al., 2020. 


\section{DISCUSSÃO}

O levantamento de informações relativas à produção de Queijos de Manteiga no estado do Amapá, demonstraram que não existe quantificação oficial da produção artesanal, não constando em estatísticas oficiais, no entanto, sabe-se da existência de numerosas unidades de produção caseiras, sendo possível afirmar que os queijos de manteiga elaborados no estado têm suas origens ligadas a fabricação artisanal, conforme a Resolução RDC ㄲ12/2001 (BRASIL, 2001b), que exige a determinação de coliformes a 45ㄷ/g (coliformes termotolerantes ou coliformes de origem fecal) em Leite de Bovinos e de Outros Mamíferos e Derivados (Queijos), as amostras tiveram expresso na análise a quantidade de contaminação de origem fecal que varia de $<3 \mathrm{NMP} / \mathrm{g}$ por amostra, logo a legislação determina a quantidade de no máximo $5 \times 10^{2} \mathrm{NMP} / \mathrm{g}$ por grama de amostra, assim pode-se concluir que as amostras estão próprias para o consumo, por apresentarem um NMP por grama de amostra dentro do aceitável para o consumo, segundo o que preconiza a legislação da vigilância sanitaria (BRASIL, 2001b).

A microbiologia analisa no alimento, a presença de microrganismos patogênicos, os tipos mais frequentes e o número de microrganismos presentes (NMP). Dessa forma se torna fundamental para analisar surtos de origem alimentar, infelizmente nem todos os métodos utilizados conseguem determinar exatamente o número de microrganismo presentes, e os tipos mais frequentes (BRINQUES GB, 2015).

A maioria dos coliformes são encontrados no ambiente, essas bactérias possuem limitada relevância na análise da condição higiênica. Devido ao fato dos coliformes serem destruídos com certa facilidade pelo calor, sua contagem é útil em testes de contaminação pós-processamento (FORSYTHE SJ, 2002).

Ademais, os microrganismos indicadores são um grupo ou espécies que, quando presentes em um alimento, podem favorecer informações sobre a ocorrência de contaminação fecal, sobre a provável presença de patógenos ou a deterioração potencial de um alimento, além de poder indicar condições sanitárias inadequadas (OLIVEIRA LA, et al., 2019).

Os resultados obtidos quanto a ausência de Salmonella, foram parecidos com os resultados alcançados por Garcia EP, et al., (2017), ao analisar amostras de queijo minas frescal e ricota, considerou-se então que o alimento pesquisado está de acordo $\mathrm{cm}$ a legislação vigente sobre Salmonella. Nesse mesmo artigo verificou-se a presença de bactérias: Klebsiella Pneumoniae e Proteus mirabilis resultados semelhantes ao observados nesta pesquisa. Os resultados sugerem, que estes queijos não foram submetidos a boas práticas de fabricação e higienização por parte de seus fabricantes e manipuladores, este fato é de grande relevância visto que a qualidade desse alimento fica prejudicada, e expõem os consumidores a possíveis enfermidades causadas pelos microrganismos anteriormente citados.

Outra bacteria importante é a Klebsiella Pneumoniae, pertencente à família das Enterobacteriaceae, no ambiente podemos encontra-las em vários lugares como por exemplo: solo, água, plantas e em esgotos sem tratamento. Humanos ficam vulneráveis a esta bactéria quando entram em contato com elas no ambiente, além disso elas são encontradas habitando a orofaringe e fezes de hospedeiros sadios. Entretanto no caso de pessoas debilitadas com alguma patogenia grave, essas bactérias conseguem facilmente se multiplicar, podendo gerar graves quadros de infecção (CUNHA VO, 2014).

Considerando a legislação utilizada para a interpretação dos resultados microbiológicos do queijo de Manteiga, constatou-se neste estudo uma análise global das amostras sem fiscalização e uma quantidade de aproximadamente $50 \%$ das amostras que se encontravam fora dos padrões de aceitabilidade para o consumo (OKURA MH e MOACIR J, 2010).

Desta forma é importante a intervenção dos orgãos de fiscalização do estado para reduzir os riscos de contaminação destes tipos de queijo que participa de forma significativa na economia regional, gerando renda aos produtores na região estudada. Adicionalmente, o estudo observou a presença de bacterias como Proteus mirabilis e Klebsiella Pneumoniae também isolados de amostras de queijo minas frescal produzidos com leite cru, leite pasteurizado e de queijo temperado, esses microrganismos podem causar: cólica abdominal, diarreia, vômito e febre (OKURA MH e MOACIR J, 2010). 
Nesse estudo foi isolado em todas as cinco amostras da feira do produtor do Buritizal a bactéria Staphylococcus xylosus que pertence ao gênero Staphylococcus que tem atualmente 47 espécies e 24 subespécies sendo que a maioria não apresenta envolvimento em surtos de infecção. No entanto algumas espécies do gênero Staphylococcus são associadas a infecções pois produzem toxinas e enzimas que são capazes de invadir várias células do corpo humano (TAPONEN S, et al., 2012; SILVA EG, 2014).

Staphylococcus xylosus também foram isolados em uma linha de produção de queijo coalho, os resultados deste achado sugerem que a presença de Staphylococcus coagulase-negativa, foi relatada a alguns surtos de intoxicação estafilocócica associados a espécies coagulase-negativa podendo representar riscos para os consumidores pois liberam enterotoxina no alimento, este fato somado a temperaturas inadequadas, $\mathrm{PH}$ do alimento e oxigênio do ambiente contribui para um potencial risco de intoxicação alimentar na população consumidora (BERTELLONI F, et al., 2015; KÜREKCI C, 2016).

Staphylococcus sciuri, foi identificado em uma amostrada de queijo tipo manteiga do bairro jardim felicidade, as espécies pertencentes a este grupo são amplamente achadas na natureza, animais silvestres, animais de estimação e de fazenda, podem ser seus hospedeiros, mas também podem colonizar humanos. Staphylococcus sciuri podem causar infecções graves como: endocardite, peritonite entre outras. As cepas diferentes de Staphylococcus são capazes de produzir uma ou mais enterotoxinas, isso representa um risco em potencial a saúde da população consumidora, por este motivo espécies Staphylococcus sciuri e Staphylococcus xylosus não podem ser ignoradas quando são detectadas em alimentos, pelo seu potencial risco de surtos alimentares (CARMO LS, et al., 2002; BERTELLONI F, et al., 2015; KÜREKCI C, 2016).

Ademais, os Staphylococcus são freqüentemente pesquisados em alimentos, sendo o queijo, um dos principais veículos causadores de toxinfecção alimentar, pois sua presença está associada a práticas de higiene e manipulação inadequadas (GUZMÁN-HERNÁNDEZ RL, et al., 2016). Também são encontrados no ambiente, em leite proveniente de vacas portadoras de mastite estafilocócica e colonizam a pele, o períneo, axilas, vagina e outros sítios do corpo de humanos e animais estimando-se que esteja presente nas fossas nasais de adultos saudáveis. Por esta razão, os manipuladores de alimentos podem se tornar portadores assintomáticos (CUNHA AP, 2012).

A identificação de Staphylococcus enterotoxigênicos em amostras de queijos, representa um grave problema de saúde pública, pois estas bactérias podem causar intoxicação, basta que sejam expostas a condições adequadas, sendo assim capazes de produzir surtos, desde que haja a ingestão de alimentos contaminados por enterotoxinas estafilocócicas (BERTELLONI F, et al., 2015; KÜREKCI C, 2016).

A lavagem das mãos e um fator de extrema importância para conter a propagação de diversos microrganismos, manipuladores de alimentos devem por sua vez higienizar suas mãos de maneira adequada sempre que estiverem manuseando alimentos e suas matérias primas, dessa maneira estão evitando que microrganismos causadores de infecções de origem alimentar contaminem o alimento (OLIVEIRA NM, et al., 2015).

Microrganismo presente no queijo, são indicativos, de contaminações sanitárias, logo podemos concluir que esse queijo não teve o devido cuidado no momento de sua produção, essa falta de atenção pode resultar em intoxicações alimentares na população consumidora, tendo em vista que esse produto é amplamente aceito comercialmente, pois se tornou um hábito alimentar de diversas regiões do país. (PATRICK HLR, et al., 2010). Segundo Brinques GB (2015), a qualidade microbiológica dos alimentos pode ser demostrada por microrganismos indicadores que estimam a sanitização dos alimentos, além de determinar aspectos de qualidade dos produtos.

Ademais, a produção e manipulação dos alimentos é de extrema importância para a prevenção de doenças transmitidas no consumo (MENDES LA, 2020). Em sintese, os resultados obtidos neste estudo permitem evidenciar que existe a necessidade de uma intervenção mais criteriosa do serviço oficial de inspeção agropecuária e vigilância sanitária, junto aos produtores e comerciantes de queijo de manteiga no estado do Amapá, propondo medidas sanitárias para uma melhoria continua da qualidade deste produto, tendo como foco a saúde do consumidor. 


\section{CONCLUSÃO}

Os queijos tipo manteiga analisados, produzidos artesanalmente e comercializados em Macapá, possuem contaminação microbiana com potencial de causar danos à saúde de quem os consome. Os resultados obtidos são importantes norteadores para as autoridades Federais, Estaduais e Municipais possam colocar em pratica ações efetivas para o controle sanitário e qualidade dos alimentos consumidos pela população. Além da fiscalização de rotina, preconiza-se, também, atuar de forma educativa junto aos produtores e vendedores, de modo a esclarecer e orientar sobre boas práticas de higiene e conservação dos produtos de origem animal que são destinados a comercialização, reduzindo o risco de serem contaminadas por microrganismos causadores de infecções de origem alimentar.

\section{AGRADECIMENTOS}

Ao laboratório Acqualitybio em nome de Maílson Rodrigues pela colaboração nas análises.

\section{REFERÊNCIAS}

1. APOLNÁRIO TCC, et al. Avaliação da qualidade Microbiológica do Queijo Minas Frescal Produzido Por Laticínios do Estado de Minas Gerais. Rev. Inst. Laticínios Cândido Tostes, 2014; 69(6): 433-442.

2. ARAÚJO JPA, et al. Uma análise histórico-crítica sobre o desenvolvimento das normas brasileiras relacionadas a queijos artesanais. Arquivo Brasileiro de Medicina Veterinária e Zootecnia. 2020; 72(5): 1845-1860.

3. AZEVEDO ACA, et al. Qualidade microbiológica do queijo de manteiga comercializado em supermercados e feiras livres da cidade de Natal, RN. Higiene Alimentar. 2017; 31(266/267): 91-95.

4. BERTELLONI F, et al. Detection of genes encoding for enterotoxins, TSST-1, and biofilm production in coagulasenegative staphylococci from bovine bulk tank milk. Dairy Sci. \& Technol 2015; 95: 341-352.

5. BRASIL. Ministério da Agricultura Pecuária e Abastecimento. Instrução Normativa no 30 de 26 de junho de 2001. Regulamento Técnico de Identidade e Qualidade de Queijo de Manteiga. Brasília: Ministério da Agricultura Pecuária e Abastecimento, 2001a.

6. BRASIL. Agência Nacional de Vigilância Sanitária - ANVISA. Resolução RDC nำ12, de 2 de janeiro de 2001. Regulamento técnico sobre os padrões microbiológicos para alimentos. Brasília: Agência Nacional de Vigilância Sanitária - ANVISA, 2001b.

7. BRASIL, Ministério do Planejamento, Orçamento e Gestão, Instituto Brasileiro de Geografia e Estatística - IBGE, Produção da Pecuária Municipal, volume 41, Rio de janeiro-RJ, 2013.

8. BRINQUES GB. Microbiologia dos Alimentos. São Paulo: Person Education do Brasil, 2015.

9. CUNHA AP. Presença de Staphylococcus coagulase positiva em queijo Minas frescal artesanal. Dissertação (Mestrado em Ciências da Saúde) - Universidade Federal de Uberlândia. 2012. 48p.

10. CUNHA VO. Bactérias multirresistentes: Klebsiella pneumoniae carbapenemase enzima KPC nas Infecções Relacionadas à Assistência à Saúde (IRAS). Monografia (Monografia em Microbiologia) - Departamento de Microbiologia da Universidade Federal de Minas Gerais. Belo Horizonte, 2014; 55p.

11. DUPIN LV. "Eu sou parte de uma classe de produtores que perdeu a sabedoria lá de trás e começou a pisar dentro das tecnologias": trajetórias camponesas na fabricação de queijos artesanais em Minas Gerais. Antípoda. Revista de Antropología y Arqueología, 2020; 40: 153-173.

12. FORSYTHE SJ. Microbiologia da Segurança Alimentar. Porto Alegre: Artmed, 2002.

13. GARCIA EP, et al. Qualidade microbiológica de queijos minas frescal e ricota comercializados na região metropolitana de Campinas-SP. Hig. aliment, 2017; 31(264/265): 132-137.

14. GERMANO PML, GERMANO MIS. Higiene e Vigilância Sanitária de Alimentos. 05. ed. Ver. e atual. Barueri, SP: Manole, 2015.

15. GUZMÁN-HERNÁNDEZ RL, et al. Aislamiento e identificacion de Brucella spp., Listeria monocytogenes, Salmonella spp. y Staphylococcus aureus en quesos frescos no pasteurizados de una zona tropical del Golfo de México. Rev Científica. 2016; 26 (5): 324-331.

16. KÜREKCI C. Short communication: Prevalence, antimicrobial resistance, and resistant traits of coagulasenegative staphylococci isolated from cheese samples in Turkey. Journal of Dairy Science. 2016. 99(4): 2675-2679.

17. MAIA ICP, et al. Análise da contaminação de utensílios em unidades de alimentação e nutrição hospitalar no município de Belo Horizonte-MG. Alimentos e Nutrição Araraquara. 2011; 22(2): 265-271.

18. MARINI JA. A pecuária familiar no Estado do Amapá. Macapá: Embrapa Amapá, 2015. 26p. (Documentos/Embrapa Amapá; ISSN 1517-4859, 84). Disponivel em: https://ainfo.cnptia.embrapa.br/digital/bitstream/item/130384/1/CPAFAP-2015-DOC-84-pecuaria-familiar-v3.pdf. Acesso em: 8 mar. 2020.

19. MATSUMOTO AY, et al. Contaminação por Coliformes Fecais em Queijos Prontos Para o Consumo. São Paulo, Revista Saúde em Foco, Edição no: 08, Ano: 2016 Disponível: https://pdfs.semanticscholar.org/05ea/8c7767308e624f574f7dba0e31fc4295dd1d.pdf. Acesso em: 10 junho 2020.

20. MENDES LA. Avaliação da condição higiênico-sanitária e pesquisa de Brucella spp. em queijos do tipo minas frescal comercializados em feiras livres de Goiânia, Brasil. Dissertação (Mestrado em Ciência Ciência Animal) - Escola de Veterinária e Zootecnia da Universidade Federal de Goiás, 2020. 106p. 
21. OLIVEIRA KML, et al. Presença de Staphylococcus aureus em queijos artesanais comercializados na cidade de Uruaçu - Goiás. Revista Eletrônica de Ciência e Tecnologia: FaseMciencias. 2015; 4(2): 63-71.

22. OLIVEIRA NM, et al. Determination of total and thermotolerant coliforms present in the hands of anglers. Revista Eletrônica de Biologia (REB). 2015; 8(1): 138-145.

23. OLIVEIRA LA, et al. Presença de coliformes em saladas cruas comercializadas em supermercados na cidade de Manaus-AM. Diversidade Microbiana da Amazônia. Manaus: Editora INPA, 2019. p. 13-19. ISBN 978-65-5633-000-6.

24. OKURA MH, MOACIR J. Avaliação das condições higiênico-sanitárias de queijos minas frescal produzidos com leite cru, leite pasteurizado e dequeijo temperado em alguns municípios da região do triângulo mineiro. Revista do Instituto de Laticínios Cândido Tostes. 2010; 65(375): 33-42.

25. PATRICK HLR, et al. Aspectos Sanitários Do Queijo Minas Artesanal Comercializado em Feiras Livres, Rev. Inst. Latic. Cândido Tostes.2010. 65 (377): 36-42.

26. PERKINS E. Food microbiology fundamentals, challenges and health implications. New York: Nova Science Publishers, 2016. cap.7, p.161-189.

27. SANTOS NS, et al. Avaliação da qualidade microbiológica de queijos do tipo coalho comercializados em Maceió-AL. Braz. J. of Develop., 2019; 5(7): 9271-9281.

28. SEIXAS VNC. Perfil da produção e caracterização de queijos artesanais da llha de Marajó e sul do Pará em duas estações do ano. Tese (Doutorado em Ciência e Tecnologia de Alimentos) - Universidade Federal de Viçosa, Minas gerais, 2014; 106p.

29. SILVA F, SILVA G. Análise microbiológica e físico-química de queijos coloniais com e sem inspeção, comercializados na microrregião de Francisco Beltrão-PR. Trabalho de Conclusão de Curso (Graduação em Tecnólogo em Alimentos) - Universidade Tecnológica Federal do Paraná, Francisco Beltrão, 2013. 58p.

30. SILVA EG. A segurança alimentar e relatos de surtos alimentares por Staphylococcus spp. Monografia (Especialização em Microbiologia aplicada a Ciências da Saúde) - Instituto de Ciências Biológicas da Universidade Federal de Minas Gerais, Belo Horizonte, 2014; 74p.

31. TAPONEN S, et al. Staphylococcus agnetis sp. Nov., a coagulase-variable species from bovine subclinical and mild clinical mastitis. International journal of systematic and evolutionary microbiology. 2012; 62(1): 61-65. 